\title{
Metabolomic analysis of SMP30/GNL knockout mice treated with fermented vegetable and fruit extract $\left(\mathrm{OM}-\mathrm{X}^{\circledR}\right)$
}

\section{Koji Wakame', Muneaki Takahata², Yasuyoshi Miyake², Eri Yasuda², Yoshie Shimomiya², Akifumi Nakata ${ }^{1}$, Kesiuke Sato ${ }^{1}$, Yoshihiro Mihara ${ }^{1}$, Akira Takaguri ${ }^{1}$, and Ken-ichi Komatu ${ }^{1}$}

${ }^{1}$ Faculty of Pharmaceutical Science, Hokkaido University of Science, 15-4-1, Maeda 7-jo, Teineku, Hokkaido 006-8585, Japan; ${ }^{2}$ BIOBANK Co., Ltd., 388-1, Hirata, Kita-ku, Okayama 700-0952, Japan.

Corresponding author: Koji Wakame, Ph.D., Department of Pharmacology, Faculty of Pharmaceutical Science, Hokkaido University of Science, 006-8585, 15-4-1, Maeda 7-jo, Teineku, Hokkaido, Japan

Submission Date: November 13 ${ }^{\text {th }}$, 2019; Acceptance Date: March 25 ${ }^{\text {th }}$, 2020; Publication Date: March $30^{\text {th }}, 2020$

Citation: Wakame K., Takataha M., Miyake Y., Yasuda E., Shimomiya Y., Nakata A., Sato K., Mihara Y., Takaguri A., Komatsu K. Metabolomic analysis of SMP30/GNL knockout mice treated with fermented vegetable and fruit extract (OM-X®). Functional Foods in Health and Disease. 2020; 10(3): 95-110. DOI: https:/doi.org/10.31989/ffhd.v10i3.674

\begin{abstract}
Background: A dietary supplement developed in Japan, OM- $\mathrm{X}^{\circledR}$, is the result of extended fermentation of dozens of edible vegetables, fruits, seaweeds, mushrooms, and includes 12 strains of Lactic acid bacteria (LAB) and Bifidobacterium. The supplements powerful antioxidant, antiinflammatory properties, and regulatory effect on metabolizing liver enzymes have been reported.

Senescence marker protein-30 (SMP30)/Gluconolactonase (GNL) Knockout (KO) mice, which lack the ability to biosynthesize Vitamin C (VC) in the body, were used in this study. The mice exhibited decreased antioxidant capacity in the blood, decreased liver function, and had poor hair growth due to the VC deficiency. The aim of the study was to examine the effects of oral
\end{abstract}


administration of $\mathrm{OM}-\mathrm{X}^{\circledR}$ on VC deficiency from the viewpoint of comprehensive analysis of liver metabolism.

Methods: SMP30/GNL KO and C57BL/6 (WT) mice were used in this study. The KO mice were divided into the following three groups: VC non-administration (VC minus), VC $(0.15 \mathrm{~W} / \mathrm{V} \%)$ administration (VC plus), and no VC plus $0.6 \% \mathrm{OM}-\mathrm{X}^{\circledR}$ administration $\left(\mathrm{OM}-\mathrm{X}^{\circledR}\right)$ groups $(\mathrm{n}=6$ per group). Mice were kept under experimental conditions until they were euthanized at week 8 (age: 16 weeks old). Body weight and plasma biochemistry levels were measured.. Metabolomic analyses of harvested livers were performed.

Results: In the VC minus group, a significant decrease in body weight and significant changes in plasma biochemistry parameters compared with the WT control or VC plus groups was observed. In the $\mathrm{OM}-\mathrm{X}^{\circledR}$ group, significant suppression or a suppressive trend was observed compared with the VC minus group. Liver metabolomic analysis showed that total adenylate levels decreased in the VC minus group, whereas $\mathrm{OM}-\mathrm{X}^{\circledR}$ administration significantly elevated total adenylate levels. In addition, the ratios of Glutathione (GSH)/ Glutathione disulfide (GSSG) and Sadenosylmethionine (SAM)/ S-adenosyl-L-homocysteine (SAH) and total glutathione levels were all significantly higher in the $\mathrm{OM}-\mathrm{X}^{\circledR}$ group than in the VC minus group. The glycerol 3phosphate/ Dihydroxyacetone phosphate (DHAP) and putrescine/spermidine ratios were elevated in the VC minus group, whereas it was significantly lower in the OM- $\mathrm{X}^{\circledR}$ group.

Conclusion: The results showed that in SMP30/GNL KO mice, some organ damage may have occurred during VC deficiency, as indicated by weight loss, hepatic injury, and changes in triglyceride-related markers. OM- $\mathrm{X}^{\circledR}$ had an effect on energy charge maintenance by elevating total adenylate levels, inducing antioxidant capacity via enhancing glutathione levels, and promoting protein synthesis, including polyamine synthesis. Altogether, the results revealed that $\mathrm{OM}-\mathrm{X}^{\circledR}$ prevents the adverse biological changes caused by VC deficiency in SMP30/GNL KO mice.

Keywords: OM-X ${ }^{\circledR}$, SMP30/GNL KO mice, Vitamin C, metabolomic analysis.

\section{INTRODUCTION:}

Vitamin C (VC) is essential for mammalian life. However, some species such as primates and guinea pigs cannot synthesize VC in vivo, while other species such as mice and rats can. VC is biosynthesized in the liver of most mammals and is involved in collagen synthesis [1] and exhibits 
antioxidative effects in vivo [2-5]. It has been determined that the inability to synthesize VC is due to mutations in the Gulono-gamma-lactone oxidase (GLO) gene. SMP30 was originally discovered as a biomolecule wherein its levels decreased with age. However, it was later found that SMP30 and GNL are the same and are involved in the penultimate step of the VC biosynthesis pathway. SMP-30 is involved one step before GLO, which is the last step of the VC biosynthesis pathway. Therefore, VC-deficient mice can be constructed by knocking out the SMP30/GNL gene [6,7].

$\mathrm{OM}-\mathrm{X}^{\circledR}$ is a fermented dietary supplement developed by Dr. Iichiroh Ohhira in Japan. OM$\mathrm{X}^{\circledR}$ is made from many kinds of vegetables, fruits, seaweeds, and mushrooms fermented using 12 strains of Lactic acid bacteria (LAB) and Bifidobacterium. OM-X ${ }^{\circledR}$ is strictly made in compliance with the International Organization for Standardization (ISO) 9001 standard in an exclusive, sanitary factory, BIOBANK Co., Ltd., (Okayama, Japan). Nutritionally, OM-X ${ }^{\circledR}$ provides carbohydrates (oligosaccharides and dietary fiber), fats (short-chain fatty acids), proteins, amino acids, some vitamins (except VC), and minerals. Our recent experiments have shown that OM-X ${ }^{\circledR}$ regulates metabolic enzymes in the livers of mice. DNA microarray analysis on OM-X ${ }^{\circledR}$ administered mice livers identified that 4 of 597 genes were upregulated and 23 of 597 genes were downregulated [8].

In this study, we investigated the effects of orally administered OM- $\mathrm{X}^{\circledR}$ in VC-deficient SMP30/GNL KO mice on blood markers and liver metabolites. In addition, we aimed to delineate the preventive effects of $\mathrm{OM}-\mathrm{X}^{\circledR}$ on low antioxidant activity and the negative metabolic impact caused by VC deficiency.

\section{MATERIALS AND METHODS}

\section{Treatment of $\mathrm{OM}-\mathrm{X}^{\circledR}$ in Mice}

SMP-30/GNL KO mice were previously generated by gene targeting techniques. Heterozygous female mice (SMP30 +/-) were mated with male KO mice (SMP30Y/-) to produce SMP30 KO (SMP30 Y/-) and WT (SMP30 Y/+) littermates. Mouse pairs were obtained from the Tokyo Metropolitan Institute of Gerontology, Japan (Japan). C57BL/6 (WT) control mice were purchased from Sankyo labo co., LTD (Japan).

Mice were bred at the Faculty of Pharmaceutical Science, Hokkaido University of Science (Hokkaido, Japan). Throughout the experiments animals were maintained on $12 \mathrm{~h}$ light/dark cycles in a controlled environment held at $23^{\circ} \mathrm{C} \pm 1{ }^{\circ} \mathrm{C}$ and $55 \% \pm 15 \%$ relative humidity.

OM-X ${ }^{\circledR}$ (BIOBANK, Okayama, Japan) was dissolved in purified water at $0.6 \%$ (W/V). Sevenweek-old male SMP30/GNL KO C57BL/6 mice were divided into the following three groups: 1) 
mice had free access to purified water without VC (VC minus group, $\mathrm{n}=6$ ), 2) mice had free access to purified water containing VC $0.15 \%(\mathrm{~W} / \mathrm{V})(\mathrm{VC}$ plus group, $\mathrm{n}=6)$, and 3) mice had free access to purified water without VC but contained the OM-X ${ }^{\circledR}$ solution $\left(\mathrm{OM}-\mathrm{X}^{\circledR}\right.$ group, $\left.\mathrm{n}=6\right)$. Age-matched male C57BL/6 $(\mathrm{WT})$ mice $(n=6)$ were used as controls. These mice were kept under the above-mentioned experimental conditions for 8 weeks. At the end of the experimental period (age: 16 weeks old), the mice were weighed and euthanized. Plasma and livers were then collected and stored at $-80^{\circ} \mathrm{C}$ for analysis (Figure 1).

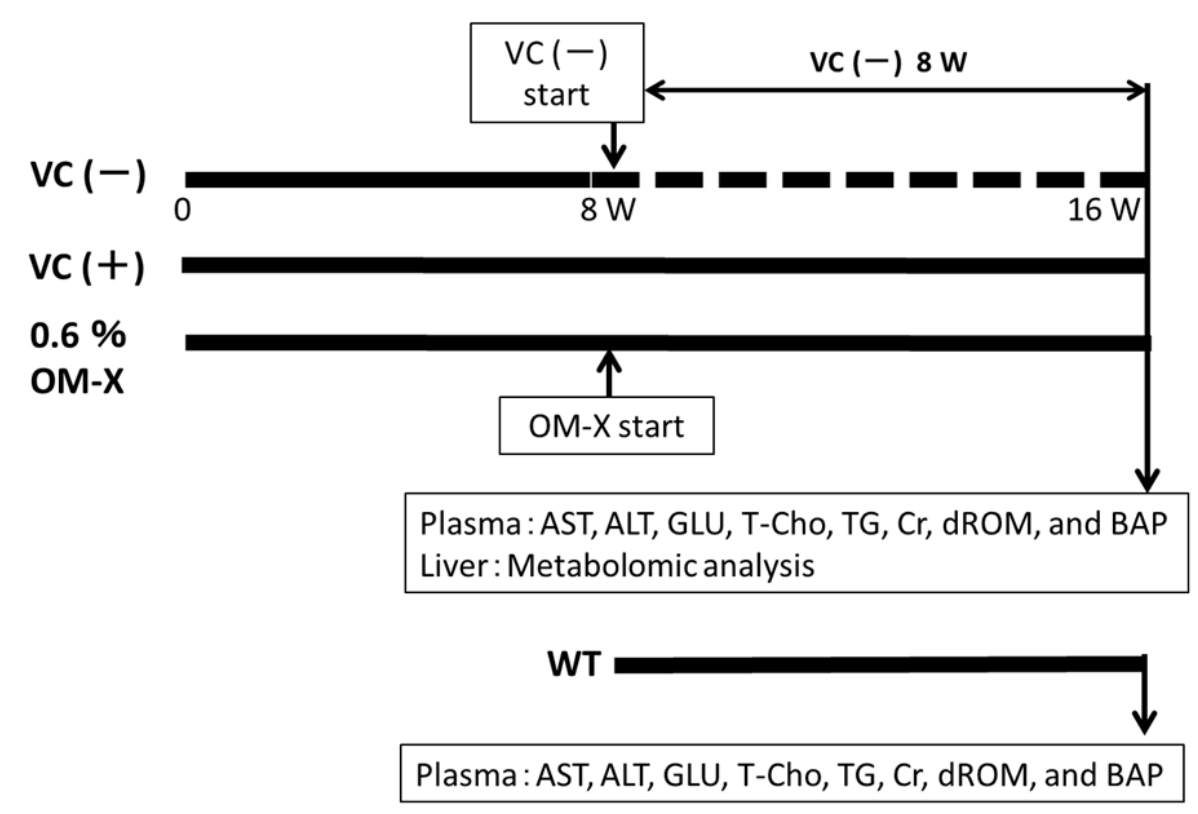

Figure 1. Experimental design of VC (-), VC (+), and 0.6\% OM-X ${ }^{\circledR}$ SMP30/GNL KO mice and WT groups (each $n=6)$. In this study, plasma biochemical analysis $(n=6)$ and liver metabolomic analysis were conducted ( $\mathrm{n}=3$, except WT). This study (protocol approval number: H28-011) was performed in accordance with the Guiding Principles for the Care and Use of Experimental Animals of Hokkaido Pharmaceutical University (published 1998, revised in 2001 and 2007).

\section{Plasma biochemical analysis}

Plasma biochemical analysis was performed at Oriental Yeast Co., Ltd. (Japan) for Aspartate aminotransferase (AST), aminotransferase (ALT), Glucose (Glu), Total cholesterol (T-Cho), Triglyceride (TG), and Creatinine (Cr) levels. In addition, Diacron-reactive oxygen metabolite (dROM) levels to assess plasma antioxidants and Biological antioxidant potential (BAP) levels were measured using the manufacturer's kit (Wismerll, Japan). 


\section{Liver Metabolomic analysis}

Acetonitrile solution $(50 \%, \mathrm{~V} / \mathrm{V})$ and the internal standard solution (52 cationic and 64 anionic substances: total 116) were added to frozen liver specimens obtained from the VC minus, VC plus, and $\mathrm{OM}-\mathrm{X}^{\circledR}$ groups (each $\left.\mathrm{n}=3\right)$, which were subjected to cell disruption, centrifugation $(2,300 \times \mathrm{g}$, $4^{\circ} \mathrm{C}, 120 \mathrm{~min}$ ), and filtration. The filtrate was dried, dissolved in the ultra-pure water, and used for downstream metabolomic analysis. Absolute quantification of 116 metabolites was calculated by CE-TOFMAS (acetolactate synthase) (Agilent CE-TOFMS System Machine No. 3, Agilent Technologies, USA) and CE-QqQMS (Agilent CE System, Agilent 6460 Triple Quad LC/MS Machine No. QqQ3, Agilent Technologies), and Principal component analysis (PCA), Hierarchical clustering analysis(HCA) heatmap generation and metabolic parameter analyses were performed. Liver metabolomic analysis was conducted by Human Metabolome Technologies Co., Ltd. (Japan).

\section{Statistical analysis}

All results are expressed as mean \pm SEM. Statistical significance was determined using the Tukey's test to compare relative plasma biochemical analyses, and the Dunnett's multiple comparison tests were used to compare relative liver metabolomic analyses. ${ }^{\mathrm{a}} \mathrm{p}<0.05,{ }^{\mathrm{b}} \mathrm{p}<0.01$, and ${ }^{c} \mathrm{p}<0.01$ were considered statistically significant with the VC (-) or WT groups. *p $<0.05$ and $* * p<0.01$ were considered statistically significant with the $\mathrm{VC}(+)$ group.

PCA, HCA heatmap generation of liver metabolomic analyses were carried out using statistical analysis software manufactured by Human Metabolome Technologies Co., Ltd. (Japan).

\section{RESULTS}

\section{Body weight and serum biochemical analysis}

Weights of VC minus group mice were significantly lower than body weights observed in the other groups. For plasma biochemical analysis, ALT and AST (indicators of liver function) levels were both significantly higher in the VC minus group than the levels in the other groups. In addition, $\mathrm{Cr}$, (an indicator of renal function) values were elevated compared with other groups. Glu and TG, (indicators of respectively sugar and lipid metabolism) levels were lower in the VC minus group compared with others. As for antioxidant indicators, increased dROM and decreased BAP levels were observed in the VC minus group compared with levels in the other groups. However, OM$\mathrm{X}^{\circledR}$ administration in mice demonstrated the opposite effect than observed in the VC minus group. Body weight and plasma biochemical analysis of each group are shown in Table 1. 
Table 1. Effects of OM-X ${ }^{\circledR}$ on SMP30/GNL KO mice.

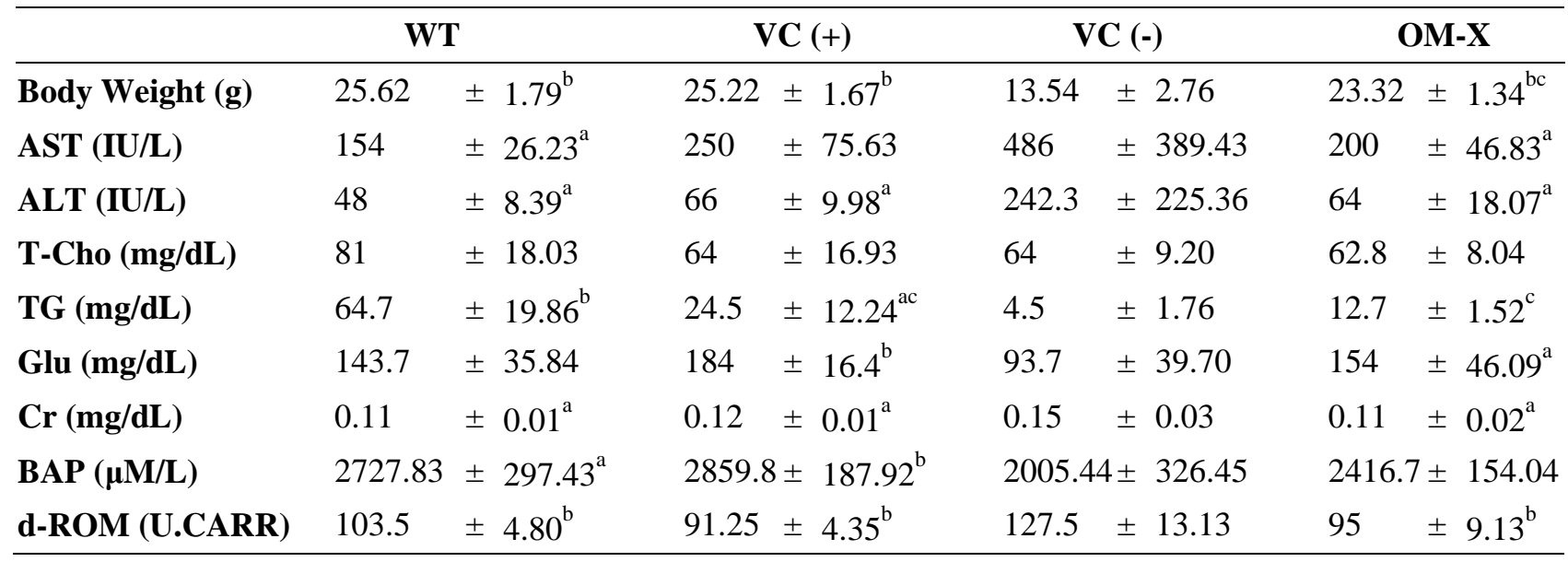

Body weight and plasma biochemical parameters aspartate aminotransferase (AST), alanine aminotransferase (ALT), glucose (Glu), total cholesterol ( T-Cho), triglyceride (TG), and creatinine $(\mathrm{Cr})$ were assessed in control and experimental groups. In addition, diacron-reactive oxygen metabolite (d-ROM; 1 U.CARR=0.08 $\mathrm{mgH} 2 \mathrm{O} 2 / \mathrm{dL})$ and biological antioxidant potential (BAP) levels were measured at 16 weeks old (mean \pm S.E.). ap $<0.05$ vs. VC(-), bp $<0.01$ vs. VC(-) and cp $<0.01$ vs. WT.

\section{Liver Metabolomic analysis}

PCA, HCA heatmap generation data are shown in Figures 2 and 3.

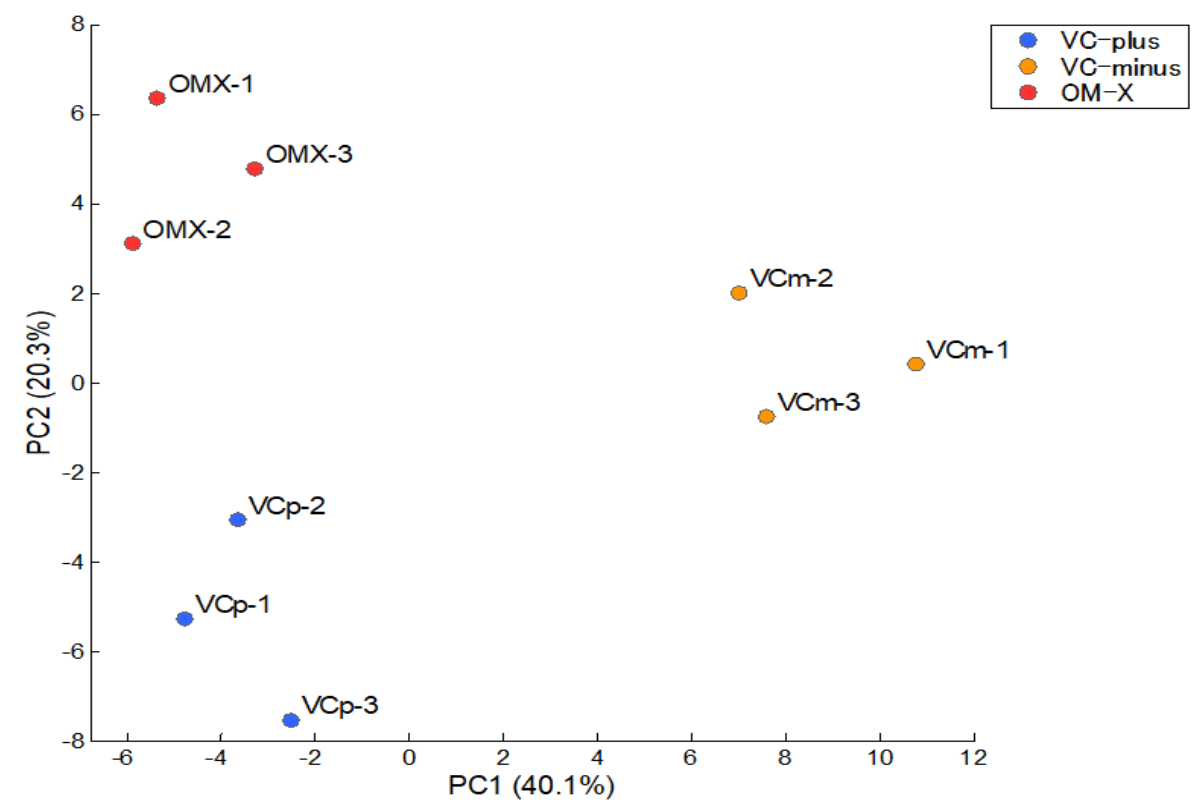

Figure 2. Two-dimensional plot of principal component analysisf liver. The first principal component is on the $\mathrm{X}$ axis, and the second principal component is on the $\mathrm{Y}$ axis. The value after the principal component identifier indicates the proportion of variance. $\mathrm{VCm}$ : $\mathrm{VC}$ minus group, $\mathrm{VCp}$ : $\mathrm{VC}$ plus group, and OMX: OM-X ${ }^{\circledR}$ group, each $n=3$ ). 


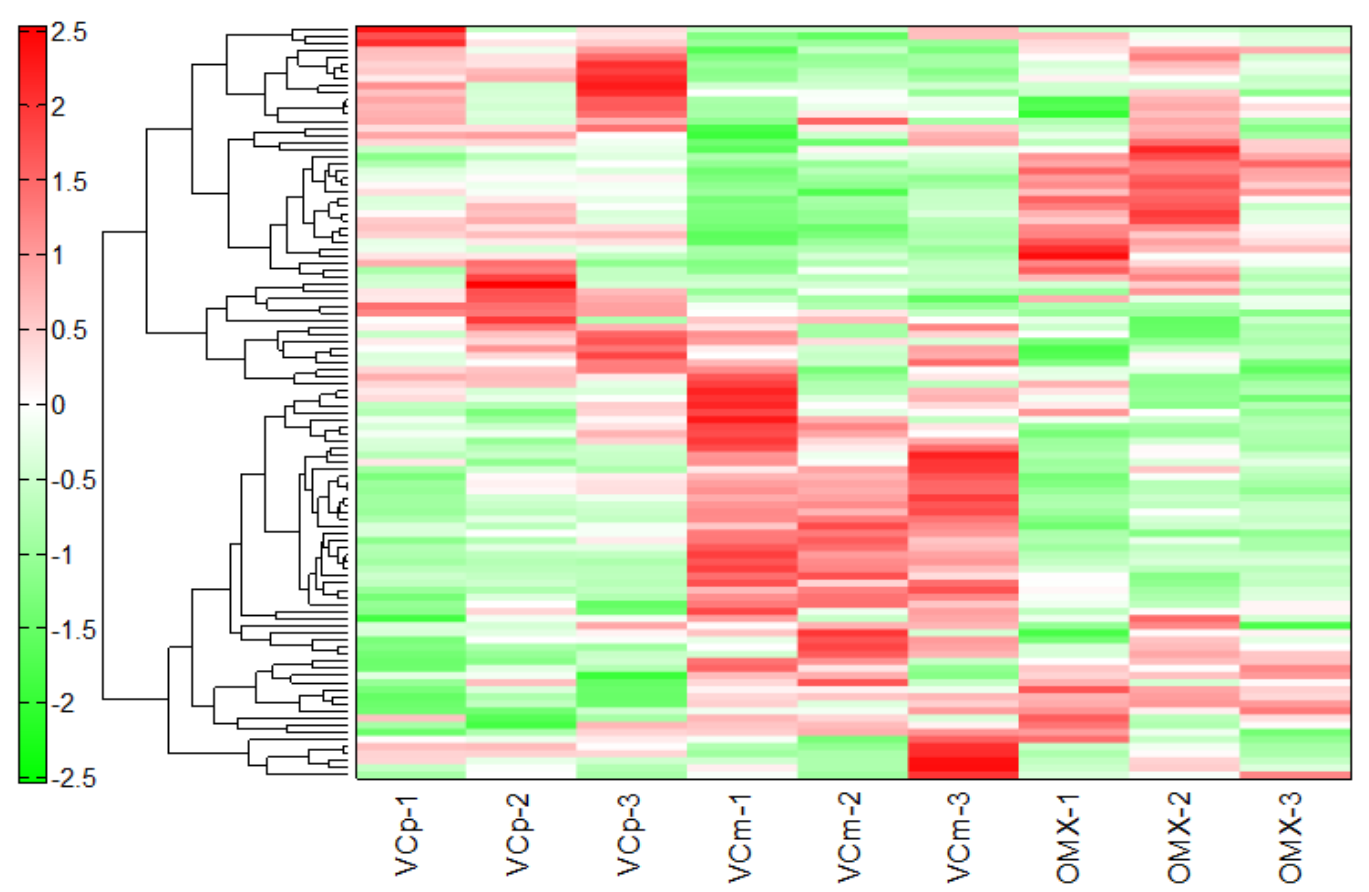

Figure 3. HCA Heat map of differentially expressed metabolites of liver. Each column corresponds to one sample (total 9 samples), and each row corresponds to a metabolite (total 116 metabolites). For 116 metabolites, red indicates metabolites expression and green indicates metabolites suppression. The metabolites are hierarchically clustered by similarity of expression profiles over the set of samples, and the samples are hierarchically clustered by similarity of expression patterns over their features. VCm: VC minus group, VCp: VC plus group, and OMX: OM-X ${ }^{\circledR}$ group, each n=3).

From 116 metabolites obtained by this metabolomic analysis, it is possible to narrow down to 30 metabolic parameters by statistical analysis, as below:

Adenylate Energy Charge, Citrulline/Ornithine, Fischer's Ratio, G6P/R5P, GSH/GSSG,

Glu/2-Oxoglutarate, Glycerol 3-phosphate/DHAP, Guanylate Energy Charge,

Lactate/Pyruvate, Malate/Asp, NADH/NAD+, NADPH/NADP+, Putrescine/Spermidine,

SAM/SAH, Total Acetyl CoA-related Amino Acids, Total Adenylate, Total Amino Acids,

Total Aromatic Amino Acids, Total BCAA, Total Essential Amino Acids,

Total Fumarate-related Amino Acids, Total Glu-related Amino Acids,

Total Glucogenic Amino Acids, Total Glutathione, Total Guanylate,

Total Ketogenic Amino Acids, Total Non-essential Amino Acids,

Total Oxaloacetate-related Amino Acids, Total Pyr-related Amino Acids,

Total Succinyl CoA-related Amino Acids

The 6/30 metabolic parameters (Bold) involved in liver detoxification, antioxidation, energy production, and protein synthesis, were significantly different between the VC plus or VC minus 
group and the $\mathrm{OM}-\mathrm{X} 囚$ group (Figures $4(\mathrm{~A})-(\mathrm{F})$ ). This figure shows also significant changes in total adenylate (ATP + ADP + AMP) levels, total glutathione (GSH + 2GSSG) levels, glutathione reduction rate (GSH/GSSG), glycerol 3-phosphate/DHAP, SAM/SAH and putrescine/spermidine ratios.

(A)

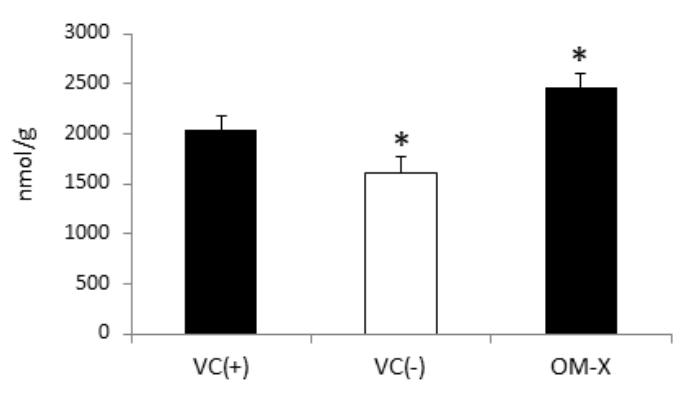

(C)

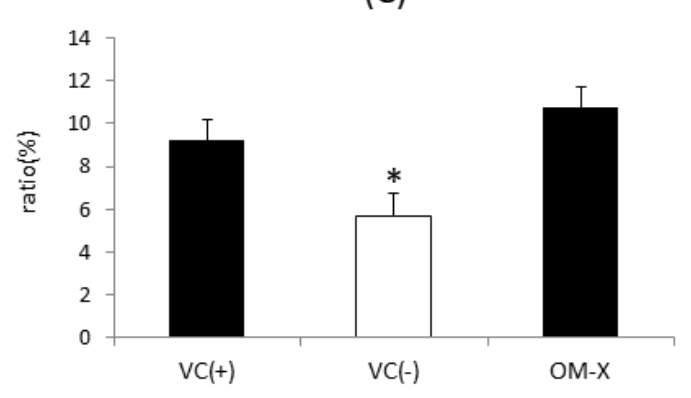

(E)

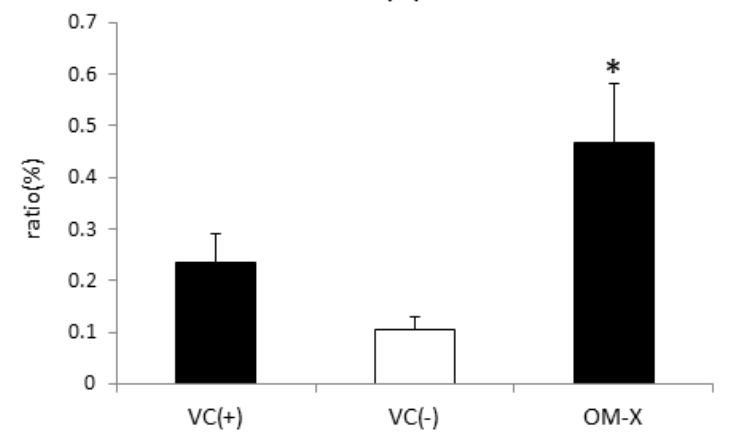

(B)

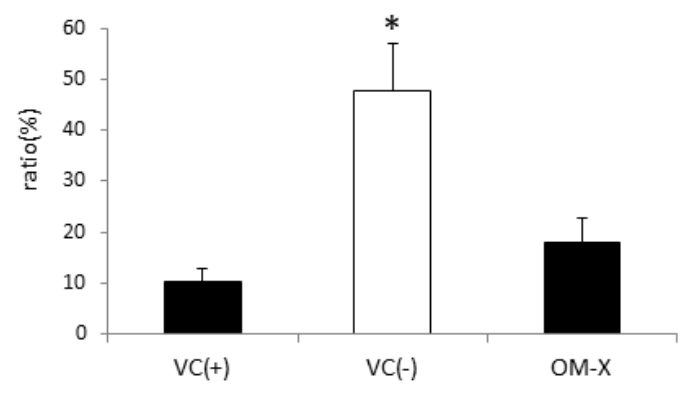

(D)

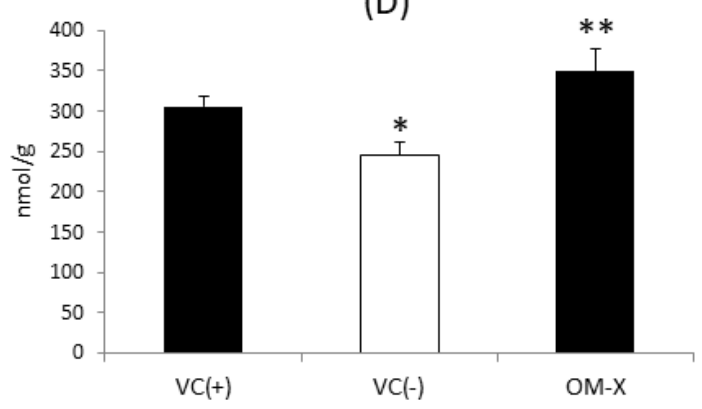

(F)

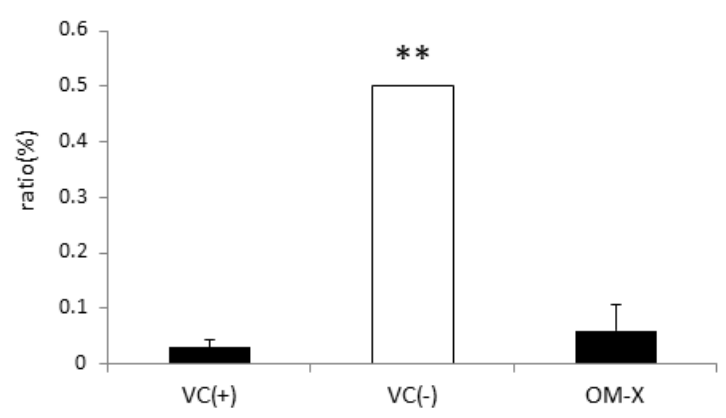

Figure 4. These metabolic parameters were significantly different between the VC plus or VC minus group and the OM- ${ }^{\circledR}$ group. $(\mathrm{A})$ Total Adenylate = ATP + ADP + AMP; (B) Glycerol3-phosphate/DHAP ratio; (C) GSH/GSSG ratio; (D) Total Glutathione = (GSH) + 2(GSSG); (E) SAM/SAH ratio; (F) Putrescine/Spermidine ratio. Results are expressed as mean \pm SE. Statistical significance was determined using the Dunnett's tests. ${ }^{*} \mathrm{p}<0.05$ and ${ }^{* *} \mathrm{p}<0.01$ regarding the VC (+) group. 


\section{DISCUSSION}

SMP30/GNL KO mice cannot synthesize VC. According to a report by Ishigami A [9], VC in plasma and organs is fully consumed about one month after VC administration is discontinued. VC deficiency in humans is referred to as "scurvy," and symptoms include hypoplasia of connective tissue and gums and subcutaneous bleeding. However, recent studies have shown that SMP30/GNL KO mice not only present with scurvy but other symptoms such as underdevelopment, defective hepatic metabolism, and hair growth insufficiency [10-13].

We investigated the effect of VC deficiency on the liver and the effectiveness of OM-X ${ }^{\circledR}$ in VC-deficient mice, which has been reported to improve the intestinal environment, modulate liver metabolic enzymes, and exert antioxidant and anti-inflammatory effect [8, 14 -16].

Changes to body weight and coat condition were seen in the mice throughout the study. Weight increase gradually decelerated in the VC minus group after VC administration was discontinued compared with other groups, and poor coat appearance was noted. At the time of dissection, the $\mathrm{OM}-\mathrm{X}^{\circledR}$ group showed significantly increased body weight compared with the VC minus group, and this group also had good coat condition.

Plasma biochemical analysis revealed decreased antioxidant activity, increased dROM and decreased BAP levels, liver damage (elevated AST and ALT values), and kidney damage (elevated $\mathrm{Cr}$ values). These findings suggested that serum antioxidant activity decreased due to lack of VC, and liver and kidney damage occurred because of reduced reactive oxygen scavenging capacity. According to a report by Maruoka H [17] et al., serum dROM increases and BAP decreases nine weeks after VC administration was discontinued in SMP30/GNL KO mice.

Meanwhile, these biochemical parameters in the plasma of OM-X $\mathrm{X}^{\circledR}$ group mice were less deviated from normal values compared with values in the VC minus group, suggesting that OM$\mathrm{X}^{\circledR}$ administration prevented liver and kidney damage. As a possible mechanism of underlying organ protection, administered $\mathrm{OM}-\mathrm{X}^{\circledR}$ may have directly or indirectly removed reactive oxygen species in the body to compensate for the antioxidant function of $\mathrm{VC}$, given a previous study demonstrated that $\mathrm{OM}-\mathrm{X}^{\circledR}$ has the capacity for antioxidant activity [18].

According to the analysis by the manufacturer, the nutritional value in OM- $\mathrm{X}^{\circledR}$ was approximately carbohydrate $(56 \%)$, lipid $(0.2 \%)$, protein $(8 \%)$, dietary fiber $(4.1 \%)$, ash $(2.1 \%)$. However, vitamin $\mathrm{C}$ was not detected. $\mathrm{OM}-\mathrm{X}^{\circledR}$ itself has active oxygen scavenging activity, and its components that contribute to its antioxidant activity include total polyphenols (0.94 g / 100 g) and organic acids (quinic acid, citric acid, lactic acid, malic acid, formic acid, acetic acid, and succinlc acid) have been reported. These antioxidant components may play an antioxidant role in VC-deficient mice[18]. 
Moreover, liver metabolomic analysis revealed clear differences in the abundance of hepatic metabolites between the $\mathrm{OM}-\mathrm{X}^{\circledR}$ administration and VC minus groups. In particular, the cluster analysis confirmed that the levels of many metabolites in the OM-X $\mathrm{X}^{\circledR}$ administration group were close to those in the VC plus group.

In other words, each metabolites change can be understood by focusing on the difference in the color of the HCA Heat map. For 116 metabolites, red indicates metabolites expression and green indicates metabolites suppression. The heat map visually indicates that the metabolites changing between the OM-X ${ }^{\circledR}$ and VC plus groups are similar. The 6/30 metabolic parameters involved in liver detoxification, antioxidation, energy production, and protein synthesis, were significantly different between the VC plus or VC minus group and the OM-X® group.

The total adenylate level (ATP + ADP + AMP) is shown as the sum of ATP, ADP, and AMP levels. It is considered to change according to the levels of de novo synthesis $[19,20]$. For example, ATP is used in reaction systems, such as glycolysis, muscle contraction, active transport, and RNA synthesis. Accordingly, OM-X® administration is suggested to be beneficial to the maintenance of vital activities related to ATP-producing systems, since it suppresses decreased adenylate levels in VC-deficient livers.

Glycerol 3-phosphate plays a central role in the glycerol phosphate shuttle and an important role in muscular organs. The glycerol 3-phosphate/DHAP ratio serves as an indirect indicator of the energy state in an organ. Furthermore, a low glycerol 3-phosphate/DHAP ratio indicates that consumption of glycerol 3-phosphate is enhanced, meaning increased production of DHAP or ATP. In this study, our results suggested that $O M-X ®$ administration is beneficial in maintaining vital activities through ATP production [21, 22].

Glutathione acts as an antioxidant to remove excess reactive oxygen species (ROS), thereby protecting cells. Glutathione is found in all cells, and in its reduced form accounts for $\geq 90 \%$ of total glutathione in normal cells. A decreased reduced/oxidized glutathione ratio (GSH/GSSG) suggests a burden of oxidative stress. Aside from antioxidant activity, reported functions of glutathione include DNA synthesis and repair, protein synthesis, removal of carcinogens, and detoxification [23-27].

The elevated ratio of reduced glutathione (GSH) to oxidized glutathione (GSSH) (i.e., predominance of the reduced form) in the OM-X® administration group suggested that $\mathrm{OM}-\mathrm{X} \AA$ can reduce cellular oxidative stress levels, prevent oxidative organ stress and disease due to excessive ROS accumulation. 
The SAM/SAH ratio is used as an index of methylation potential in cells. SAM is also involved in detoxification metabolism mechanisms through methylation of catechol compounds and other substances in the liver. Moreover, a recent study suggested that SAM levels contribute to extended life span in Drosophila [28-33].

Putrescine and spermidine are representative polyamines. The capacity of polyamine synthesis is known to decrease as age advances.. In particular, the reported effects of spermidine include promoting protein synthesis, anti-inflammation, antioxidation, and promoting hair growth. [34- 37] In terms of elevated SAM levels, the significance of OM-X ${ }^{\circledR}$ administration is expected to be not only activation of detoxification but also promotion of protein synthesis and anti-aging effects of spermidine.

Thus, OM- $\mathrm{X}^{\circledR}$ in VC deficient mice was found to restore changes in liver metabolites. Particularly, it is useful from the viewpoint of liver detoxification, antioxidation, energy production, and protein synthesis. However the role of $\mathrm{OM}-\mathrm{X}^{\circledR}$ in maintenance of the liver metabolites is not clear. On the other hand, it is expected that these metabolites may contribute to maintenance of the general state, protection of organ damage, and blood antioxidant activity of the VC deficient mice.

Finally, the maintenance of metabolites by administration to $\mathrm{OM}-\mathrm{X}^{\circledR}$ will be discussed in terms of improving the intestinal environment. According to recent studies, melanoidin is a characteristic component found in $\mathrm{OM}-\mathrm{X}^{\circledR}$, and it has been reported that this component may improve intestinal microflora [38]. Changes in the intestinal flora affect the metabolism of amino acids and glutathione in the mouse host, and are considered to be a starting point for studies on metabolic disease and the intestinal environment. In fact, since OM-X ${ }^{\circledR}$ has the function of suppressing intestinal inflammation, it is expected that studies will be conducted on the effects on metabolic function in vivo through improvement of intestinal flora in the future.

\section{CONCLUSION}

It is suggested that VC deficiency disrupts the complex liver metabolic system. OM-X ${ }^{\circledR}$ administration may help to maintain organ function, liver metabolite changes, body weight change and coat condition. However, the mechanism of action for OM-X ${ }^{\circledR}$ is very complicated. In the future, research targeting a small number of metabolites is needed.

List of Abbreviations: Adenosine diphosphate (ADP),Alanine aminotransferase (ALT), Adenosine monophosphate (AMP), Aspartate aminotransferase (AST), Adenosine triphosphate (ATP), Biological antioxidant potential (BAP), Capillary electrophoresis-time-of-flight mass 
spectrometry (CE-TOFMS), Capillary electrophoresis-triple-quadrupole mass spectrometry (CEQqQMS), Creatinine (Cr), Dihydroxyacetone phosphate (DHAP), Diacron-reactive oxygen metabolite (d-ROM), Gulono-gamma-lactone oxidase (GLO), Glucose (Glu), Gluconolactonase (GNL), Glutathione (GSH), Glutathione disulfide (GSSG), Hierarchical clustering analysis (HCA), International organization for standardization (ISO), Knockout (KO), Lactic acid bacteria (LAB), Nicotinamide adenine dinucleotide (NADH or NAD+), Principal component analysis (PCA), Reactive oxygen species (ROS), S-adenosyl-L-homocysteine (SAH), S-adenosylmethionine (SAM), Standard error (SE), Senescence marker protein-30 (SMP-30), Total cholesterol (T-Cho), Triglyceride (TG), Vitamin C (VC), Wild type (WT)

Author contributions: K.W., Y.M., K.K., and M.T. designed the research protocol. Y.M., E.Y., and Y.S. provided OM-X ${ }^{\circledR}$ samples and data. A.N., K.S., Y.M., and A.T. were the study investigators and analyzed the plasma biochemical data. K.Y. performed statistical analysis. K.W. and M.T. wrote the manuscript. K.W., A.N., and K.S. reviewed and edited the manuscript. K.W. had the primary responsibility for the final content. All authors read and approved the final version of the manuscript.

Competing interests: Muneaki Takahata, Yasuyoshi Miyake, Eri Yasuda, and Yoshie Shimomiya are employees of BIOBANK Co., Ltd. BIOBANK has food products containing OM-X ${ }^{\circledR}$.

Acknowledgments and Funding: We would like to thank Human Metabolome Technologies, Inc. (Yamagata) for performing the metabolomic analysis. This work was supported by grants from BIOBANK Co., Ltd.

\section{REFERENCES}

1. Pinnell SR. Regulation of collagen biosynthesis by ascorbic acid: a review. Yale J Biol Med 1985, 58(6):553-559.

2. Kondo Y, Sakuma R, Ichisawa M, Ishihara K, Kubo M, Handa S, Mugita H, Maruyama N, Koga H, Ishigami A. Potato chip intake increases ascorbic acid levels and decreases reactive oxygen species in SMP30/GNL knockout mouse tissues. J Agric Food Chem 2014, 62: 9286-9295.

3. Amano A, Sato Y, Kishimoto Y, Takahashi K, Handa S, Aigaki T, Maruyama N, Ishigami A. Effects of ascorbic acid deficiency on protein and lipid oxidation in livers from SMP30/GNL knockout mice. J Nutr Sci Vitaminol 2014, 59(6):489-495. 
4. Sato Y, Amano A, Kishimoto Y, Takahashi K, Handa S, Maruyama N, Ishigami A.Ascorbic acid prevents protein oxidation in livers of senescence marker protein30/gluconolactonase knockout mice. Geriatr Gerontol Int 2014, 14(4):989-995.

5. Ratnam DV, Ankola DD, Bhardwaj V, Sahana DK, Kumar MN. Role of antioxidants in prophylaxis and therapy: A pharmaceutical perspective. J Control Release 2006, 20;113(3):189-207.

6. Nishikimi M, Koshizaka T, Ozawa T, Yagi K. Occurrence in humans and guinea pigs of the gene related to their missing enzyme L-gulono-gamma-lactone oxidase. Arch Biochem Biophys 1988, 267: 842-846.

7. Kondo Y, Inai Y, Sato Y, Handa S, Kubo S, Shimokado K, Goto S, Nishikimi M, Maruyama N, Ishigami A. Senescence marker protein 30 functions as gluconolactonase in L-ascorbic acid biosynthesis, and its knockout mice are prone to scurvy. Proc Natl Acad Sci 2006, 103: 5723-5728.

8. Wakame K, Nakata A, Sato K, Mihara Y, Takahata M, Miyake Y, Okada M, Shimomiya Y, Komatsu K. Fermented vegetable and fruit extract $\left(\mathrm{OM}-\mathrm{X}^{\circledR}\right)$ stimulates murine gastrointestinal tract cells and RAW264.7 cells in vitro and regulates liver gene expression in vivo. Integr Mol Med 2017, 4:1-5.

9. Ishigami A. Anti-aging research using SMP30/GNL knockout mice.Yakugaku Zasshi 2010, 130(1):25-28.

10. Park JK, Jeong DH, Park HY, Son KH, Shin DH, Do SH, Yang HJ, Yuan DW, Hong IH, Goo MJ, Lee HR, Ki MR, Ishigami A, Jeong KS. Hepatoprotective effect of Arazyme on CCl4-induced acute hepatic injury in SMP30 knock-out mice. Toxicology 2008, 246(2-3):132-142.

11. Arai KY, Sato Y, Kondo Y, Kudo C, Tsuchiya H, Nomura Y, Ishigami A, Nishiyama T. Effects of vitamin $\mathrm{C}$ deficiency on the skin of the senescence marker protein-30 (SMP30) knockout mouse. Biochem Biophys Res Commun. 385: 478-483.

12. Sato Y, Uchida E, Aoki H, Hanamura T, Nagamine K, Kato H, Koizumi T, Ishigami A. Acerola (Malpighia emarginata DC.) Juice intake suppresses UVB-induced skin pigmentation in SMP30/GNL knockout hairless mice. PLoS One 2009, 12: e0170438.

13. Wakame K, Komatsu K, Nakata A, Sato K, Takaguri A, Masutomi H, Nagashima T, Uchiyama H. Transcriptome Analysis of Skin from SMP30/GNL Knockout Mice Reveals the Effect of Ascorbic Acid Deficiency on Skin and Hair. in vivo 2018, 31: 599-607.

14. Takahata M, Fremont M, Desreumaux P, Rousseaux C, Dubuquoy C, Shimomiya Y, Nakamura Y, Miyake Y. Evaluation of therapeutic properties of fermented vegetable 
extract $\left(\mathrm{OM}-\mathrm{X}^{\circledR}\right)$ in the model of colitis induced by Citrobacter rodentium in mice. $\mathrm{J}$ of Funct Foods 2014, 10:117-127.

15. Itoh T, Miyake Y, Yamaguchi T, Tsukaguchi S, Mitarai R, Enomoto M, Ensho S, Shimomiya Y, Nakamura Y, Ando M, Tsukamasa Y, Takahata M. OM-X®, a fermented vegetables extract, facilitates muscle endurance capacity in swimming exercise mice. Nat Prod Comm 2017, 12(1):111-114.

16. Itoh T, Miyake Y, Onda A, Kubo J, Ando M, Tsukamasa Y, Takahata M. Immunomodulatory effects of heat-killed Enterococcus faecalis TH10 on murine macrophage cells. MicrobioOpen 2012, 1(4):373-380.

17. Maruoka H, Ishigami A, Kishimoto $\mathrm{Y}$. The effect of vitamin c c-consumption on the oxidative stress regulation system in SMP30/GNL knockout mice. JJCAM 2013, 10 (2): 63-68.

18. Itoh T, Miyake Y, Kasashima T, Shimomiya Y, Nakamura Y, Ando M, Tsukamasa Y, Takahata M. OM-X ${ }^{\circledR}$, fermented vegetables extract suppresses antigen-stimulated degranulation in Rat Basophilic Leukemia RBL-2H3 cells and passive cutaneous anaphylaxis reaction in mice. Nat Prod Comm 2015, 10(9):1597-1601.

19. Spragg RG, Hinshaw DB, Hyslop PA, Schraufstätter IU, Cochrane CG. Alterations in adenosine triphosphate and energy charge in cultured endothelial and P388D1 cells after oxidant injury. J Clin Invest 1985, 76(4):1471-1476.

20. Cochrane CG. Cellular injury by oxidants. Am J Med 1991, 30;91(3C):23S-30S.

21. Fahien LA, Laboy JI, Din ZZ, Prabhakar P, Budker T, Chobanian M. Ability of cytosolic malate dehydrogenase and lactate dehydrogenase to increase the ratio of NADPH to NADH oxidation by cytosolic glycerol-3-phosphate dehydrogenase. Arch Biochem Biophys 1999, 15;364(2):185-94.

22. Cerdán S, Rodrigues TB, Sierra A, Benito M, Fonseca LL, Fonseca CP, García-Martín ML. The redox switch/redox coupling hypothesis. Neurochem Int. 48(6-7):523-530.

23. Lu SC. Glutathione synthesis. Biochim Biophys Acta 2012, 1830(5):3143-3153. Review

24. Lu SC. Regulation of glutathione synthesis. Mol Aspects Med 2009, 30(1-2):42-59.

25. Dalton TP, Chen Y, Schneider SN, Nebert DW, Shertzer HG. Genetically altered mice to evaluate glutathione homeostasis in health and disease. Free Radic Biol Med 2004, 37(10):1511-1526. 
26. Chen Y, Dong H, Thompson DC, Shertzer HG, Nebert DW, Vasiliou V. Glutathione defense mechanism in liver injury: insights from animal models. Food Chem Toxicol 2013, 60:38-44.

27. Anderson ME. Glutathione: an overview of biosynthesis and modulation. Chem Biol Interact 1998, 24;111-112:1-14.

28. Barbosa PR, Stabler SP, Trentin R, Carvalho FR, Luchessi AD, Hirata RD, Hirata MH, Allen RH, Guerra-Shinohara EM. Evaluation of nutritional and genetic determinants of total homocysteine, methylmalonic acid and S-adenosylmethionine/Sadenosylhomocysteine values in Brazilian childbearing-age women. Clin Chim Acta 2008, 388(1-2):139-147.

29. Ivanov AV, Dubchenko EA, Kruglova MP, Virus ED, Bulgakova PO, Alexandrin VV, Fedoseev AN, Boyko AN, Grachev SV, Kubatiev AA. Determination of Sadenosylmethionine and S-adenosylhomocysteine in blood plasma by UPLC with fluorescence detection. J Chromatogr B Analyt Technol Biomed Life Sci 2019,15;1124:366-374.

30. Villalba M, Varela I, Mérida I, Pajares MA, Martínez del Pozo A, Mato JM. Modulation by the ratio S-adenosylmethionine/S-adenosylhomocysteine of cyclic AMP-dependent phosphorylation of the $50 \mathrm{kDa}$ protein of rat liver phospholipid methyltransferase. Biochim Biophys Acta 1985, 12;847(3):273-279.

31. Schalinske KL, Steele RD. Variations in S-adenosylmethionine, Sadenosylhomocysteine and adenosine concentrations in rat liver. Biofactors 1992, 3(4):265-268.

32. Henning SM, McKee RW, Swendseid ME. Hepatic content of S-adenosylmethionine, S-adenosylhomocysteine and glutathione in rats receiving treatments modulating methyl donor availability. J Nutr 1989, 119(10):1478-1482.

33. Obata F, Miura M. Enhancing S-adenosyl-methionine catabolism extends Drosophila lifespan. Nat Commun 2015, 18;6:8332.

34. Brosnan ME, Symonds GW, Hall DE, Symonds DL. Polyamine metabolism in liver of young rats. Biochem J 1978, 15;174(3):727-232.

35. Soda K, Dobashi Y, Kano Y, Tsujinaka S, Konishi F. Polyamine-rich food decreases age-associated pathology and mortality in aged mice. Exp Gerontol 2009, 44(11):727732.

36. Hall DE, Symonds GW, Symonds DL, Brosnan ME. Analysis of spermidine and spermine in rat liver. Effect of hypophysectomy on polyamine concentrations. Can J Biochem 1978, 56(5):291-295. 
37. Madeo F, Eisenberg T, Pietrocola F, Kroemer G. Spermidine in health and disease. Science 2018, 26;359(6374).

38. Takahata M, Frémont M, Desreumaux P, Rousseaux C, Dubuquoy C, Shimomiya Y, Nakamura Y, Miyake Y. Evaluation of therapeutic properties of fermented vegetables extract $(\mathrm{OM}-\mathrm{X} 囚)$ in the model of colitis induced by Citrobacter rodentium in mice. $\mathrm{J}$ Fun Foods 2014, 10:117-127. 